\title{
The EEG in Alzheimer type dementia: lack of progression with sequential studies
}

\author{
A.D. Rae-Grant, W.T. Blume, K. Lau, M. Fisman, V. Hachinski and H. Merskey
}

\begin{abstract}
Our findings dispel the commonly held belief that the EEG always worsens progressively in dementia of the Alzheimer's type. In a continuing cohort analytical study of dementia, 139 patients with Alzheimer's disease and 148 controls were studied for EEG abnormalities and progression. EEGs were read without knowledge of the previous EEGs or clinical condition, and classified according to the presence of diffuse delta or theta, bisynchronous spikes, projected activity, and focal activity. EEGs were significantly different in the two groups. EEG scores generally worsened over 1-4 years, but most of the subjects showed no alteration in their EEG scores. A few patients with Alzheimer's disease showed improvement of EEG findings.
\end{abstract}

RÉSUMÉ: L'EEG dans la démence de type Alzheimer: l'absence de progression lors d'études séquentielles. Nos observations écartent une opinion courante que l'EEG s'aggrave toujours progressivement dans la démence de type Alzheimer. Nous avons étudié l'EEG de 139 patients et de 148 témoins pour détecter les anomalies et leur progression à l'intérieur d'une étude longitudinale par la méthode analytique de cohorte sur la démence. Les EEG étaient lus dans l'ignorance des EEG antérieurs et de l'état clinique du patient et classifiés selon la présence ou l'absence d'ondes delta ou thêta, de pics bisynchrones, d'activité projetée et d'activité focale. Les EEG étaient significativement différents dans les deux groupes. Les résultats des EEG s'aggravaient en général sur une période de 1 à 4 ans, mais chez la plupart des sujets, il n'y avaient pas d'altérations dans les résultats de leurs EEG. Chez quelques patients atteints de maladie d'Alzheimer, il y eut amélioration des constatations électroencéphalographiques.

Can. J. Neurol. Sci. 1986; 13:407-409

Many studies of the EEG in Alzheimer's disease have been reported in the literature, but only recently has emphasis shifted to studies which assess longitudinal changes in this disorder. ${ }^{1-8}$ As well, changes in the understanding of this disease have made old studies using outdated diagnostic criteria difficult to correlate with more recent data. ${ }^{9-11}$

Previous reports have emphasized the tendency of abnormalities to worsen in the EEG of Alzheimer's disease, with a progressive increase in theta and delta activity, and with loss of faster rhythms. However, most of the reports have extrapolated from groups of patients tested at one time. ${ }^{7,8,12-15}$ The few reports with repeated testing date from the 1960's, and a number of these patients stayed the same in their EEG pattern or improved,.$^{5,7.16}$ Only a very recent study $^{2}$ has shown, with power spectral analysis, that their patients slowed in overall background rhythm over 1 and 2.5 years. However, the authors did not report whether a subgroup of their patients stabilized or improved during this follow-up.

\section{METHODS}

This report is part of the work of the Dementia Study Group at the University of Western Ontario. Patients are referred to the group with an initial diagnosis of dementia, and diagnosed by a neurological examination (V.H.). A cohort of age matched controls are also studied. We, and others, have found that Alzheimer's disease was present in 28 of 31 patients with this clinical diagnosis in whom autopsy results were obtained (Wade, et al, unpublished data). EEGs are performed on a yearly basis by two electroencephalographers (W.T. Blume and R.S. McLachlan). Informed consent is obtained from all participants. Sixteen channel awake EEGs are performed using collidionapplied electrodes according to the Ten Twenty System for a minimum of 30 minutes. EEGs are read knowing the age but the electroencephalographer is unaware of the clinical condition and of results of any previous EEGs.

The EEGs are classified as follows: 0 ) uninterpretable because of excessive artifact from impaired patient cooperation, 1) Nor- 
Table 1: Sequential EEG data in Patients and Controls, including presence of focal abnormalities and triphasic waves

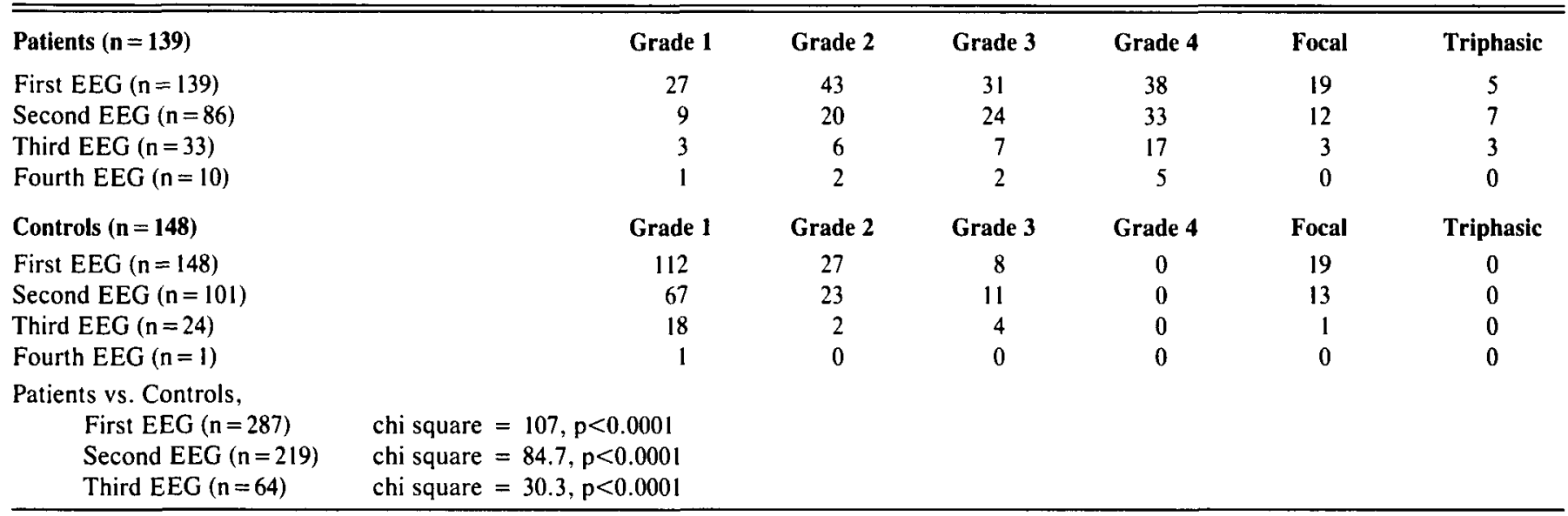

Table 2: EEG data comparing first and second, first and third, and first and fourth sequential EEGs in patients and controls

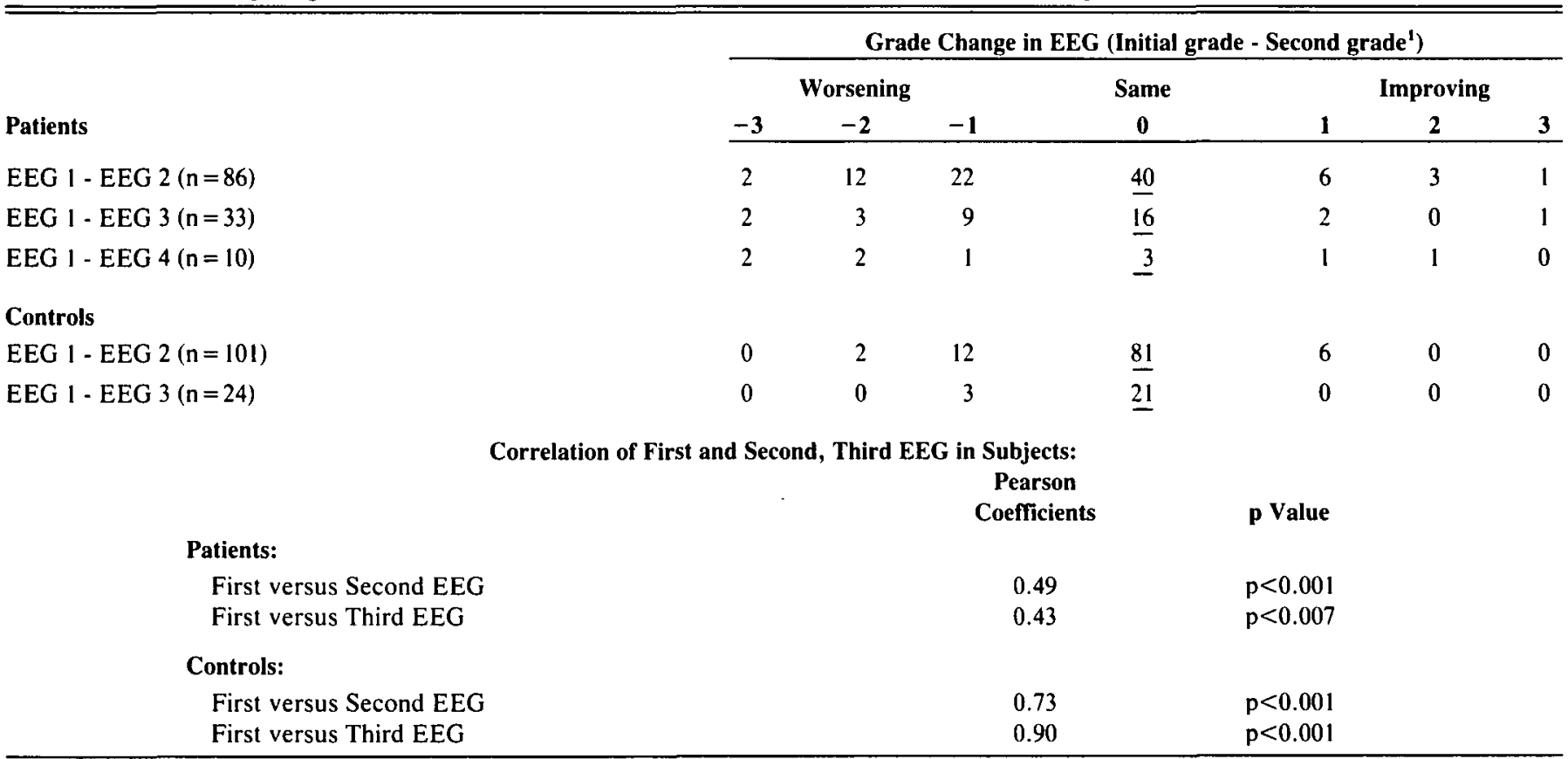

'Negative scores indicate a worsening of EEG grade, 0 indicates no change, and positive scores indicate improving EEG.

mal for age, 2) Mild but definite excessive theta and/or bitemporal spikes, 3) Moderate excess theta diffusely and/or bursts of bisynchronous, diffuse rhythmic 2-3 hertz waves, 4) One or more of: persistent diffuse delta, bisynchronous spikes or sharp waves, and triphasic waves, 5) Focal abnormalities. Pertinent statistical analysis was obtained using the Statistical Package for the Social Sciences. ${ }^{17}$

\section{ReSULTS}

139 patients with Alzheimer's disease and 148 controls were studied for this analysis. 53 patients had one EEG study only, 53 had two studies, 23 had 3 studies, and 10 had 4 or more. Among the controls, 47 had one study, 77 had two, 23 had three, and 1 control had four EEGs.
On a qualitative basis, the EEG findings were similar to those in many previous studies; there were numerous examples of slowing of the background rhythm (theta, delta activity), superimposition of focal abnormalities, spikes, sharp waves, asymetries, and triphasic waves.

In the first three EEG studies the patients' EEGs were significantly more abnormal than the controls' (Table 1). In the fourth, due to small numbers, statistical evaluation was omitted. As in other studies, however, there was some overlap between the patient and control EEG results. Thus, 39 of the patients' 268 studies were normal ( $14 \%$ ), and 75 of 274 control studies (27\%) were mildly to moderately abnormal. Focal abnormalities for age appeared in first EEGs of $13 \%$ and $14 \%$ of patients and controls, respectively. Triphasic waves were found only in the patients ( 15 of 268 EEG studies, $5.6 \%$ ), and were always associ- 
ated with other severe disturbances such as delta grade one to three, and/or bisynchronous spikes or sharp waves. Excessive delta activity (Grade 4) was never found in the control group.

We compared the first EEG done in each patient and control with the second, third, and fourth EEG (Table 2). In both the patient and control group, there was a tendency for the EEG scores to worsen from the first to the second, third and fourth study. However, there was an even greater tendency for the studies to remain the same. Indeed, a small percentage of the dementia patients' EEGs showed improvement (12\% improving from initial to final study) and in 3 patients this was apparent over a 4 year follow-up period. The EEGs did not, therefore, show a monotonous progression to slower and more malignant rhythms, but varied in progression and pattern. In both the controls and the patients, the first EEG correlated strongly with the second EEG and third EEG performed in each subject, emphasizing the overall stability of the EEG pattern (Table 2).

These results suggest that the EEG, at least over this length of follow-up, may improve, stay the same or worsen; indeed more than half of our patients did not show a trend towards worsening during the study period. We feel that further study with longer follow-up, and attention to subgroups defined by EEG progression is needed in this area.

\section{ACKNOWLEDGEMENTS}

The authors would like to acknowledge the work which Dr. M.J. Ball and Dr. R.S. McLachlan contributed to this study. Preparation of the work was supported by the Medical Research Council of Canada Program Grant 21, the National Health Research and Development Program of Health and Welfare Canada Grant 6606-2889-44, and the National Institute on Aging Grant AGNS 03047.

\section{REFERENCES}

1. Coben LA, Danziger WL, Berg L. Frequency analysis of the resting awake EEG in mild senile dementia of the Alzheimer type. EEG and Clin Neurophys 1983; 55: 372-380.

2. Coben LA, Danziger WL, Storandt M. A longitudinal EEG study of mild senile dementia of Alzheimer type: changes at 1 year and 2.5 years. EEG and Clin Neurophys 1985; 61: 101-112.

3. Duffy FH, Albert MS, McAnulty G. Brain electrical activity in patients with presenile and senile dementia of the Alzheimer's type. Ann Neurol 1984; 16: 439-448.

4. Frey T, Sjogren $H$. The EEG in presenile and senile patients. Acta Psych Neurol Scand Suppl 1956; 106: 72-73.

5. Gordon EB. Serial EEG studies in presenile dementia. Br J Psychiat 1968; 114: 779-780.

6. Gordon EB, Sim M. The EEG in presenile dementia. J Neurol Neurosurg Psychiat 1967; 30: 285-

7. Johanneson G, Brun A, Gustafson I, Ingvar DH. EEG in presenile dementia related to cerebral blood flow and autopsy findings. Acta Neurol Scand 1977; 56: 89-103.

8. Johanneson G, Hagberg B, Gustafson L, Ingvar DH. EEG and cognitive impairment in presenile dementia. Acta Neurol Scand 1979; 59: 225-240.

9. Diagnostic and statistical manual of mental disorders. 3rd ed. American Psychiatric Association, 1980.

10. McKhann G, Drachman D, Folstein M, et al. Clinical diagnosis of Alzheimer's disease: report of the NINCDS-ADRDA Work Group. Neurology 1984; 34: 939-943.

11. Cummings JL, Benson DF. Dementia: A clinical approach. Boston, Butteworths, 1983.

12. McAdam W, Robinson RA. Senile intellectual deterioration and the EEG: A quantitative correlation. J Ment Sci 1956; Oct.: 819-825.

13. McAdam W, Robinson RA. Prognosis in Senile Deterioration. J Ment Sci 1957; Oct.: 821-823.

14. Merskey H, et al. Correlative studies in Alzheimer's disease. Prog Neuro-Psychopharmacol \& Biol Psychiat 1985; 9: 509-514.

15. Merskey $\mathrm{H}$, et al. Relationship between psychological measurements and cerebral organic changes in Alzheimer's disease. Le Journal Canadien des Sciences Neurologiques 1980; 7(1): 45-49.

16. Letemendia F, Pampaglione G. Clinical and Electroencephalographic Observations in Alzheimer's disease. J Neurol Neurosurg Psychiatr 1958; 21: 167-178.

17. Nie NH, Hull CH, Jenkins JG, et al. Statistical package for the social sciences. Ed 2, New York, McGraw-Hill, 1975. 